\title{
A moralidade em uma cidade tropical: Belém no século XIX em Viagem do naturalista inglês Henry Walter Bates
}

\section{The morality issue in a tropical city: Belém circa XIX century in English naturalist Henry Walter Bates's travel}

Marcelo Werner da Silva - Doutor em Geografia pela UFRJ. Professor da Universidade Federal Fluminense, Campos dos Goytacazes, RJ. Área de atuação: Geografia urbana histórica e geografia da circulação.E-mail: marcelows@id.uff.br e silvamw@yahoo.com.br

\section{Resumo}

Análise do livro de viagem do naturalista Henry Walter Bates, que esteve na Amazônia no período de 1848 a 1859 estudando e coletando amostras de animais e plantas da região. Destacamos suas observações sobre a cidade de Belém do Pará, ponto de chegada e sua base operacional durante mais de três anos. Tais observações configuram um painel sobre a cidade, com citações a respeito dos mais diversos aspectos de sua vida social, política e econômica. De sua análise, destacamos as representações portadoras de conteúdos ideológicos, como sua leitura sobre a moralidade em uma cidade nos trópicos, em que se percebe a carga ideológica e de pré-conceitos inerente a descrições de realidades estranhas às referências culturais do observador. Por outro lado, pode-se constatar como a cidade, com seu cotidiano e suas práticas, foi vista por alguém desacostumado a seu cotidiano.

\section{Palavras-chave}

Viajantes. Livros de viagem. Visões urbanas. Belém do Pará. Século XIX.

\begin{abstract}
Analysis by the naturalist Henry Walter Bates's travel book, who lived in Amazônia from 1848 to 1859, studying and collecting animal and plant's samples from the region. We can highlight his observations about the city of Belém do Pará, where he arrived and which was his operational basis for more than three years. Such observations display a panel about the city, with quotes about the most different aspects of its social life, politics, and economy. From his points of view, we point out the representations that carry ideological issues; such as, his views about the morality in a tropical city, in which it is noticeable, the ideological charge and prejudge intrinsic to the descriptions of strange realities, contrasting the observer cultural references. On the other hand, it is possible to visualize how someone not used to its habits witnessed the city, its daily routine and habits.
\end{abstract}

\section{Keywords}

Travelers. Travel book. Urban visions. Belém do Pará. XIX century. 


\section{INTRODUÇÃO}

$\mathrm{O}$ artigo objetiva analisar as descrições da paisagem urbana da cidade de Belém/PA, observadas no livro de Henry Walter Bates, "El Naturalista por el Amazonas". Consideraram-se os relatos de viajantes estrangeiros como portadores de uma leitura ideológica, que relaciona o que está sendo observado através de parâmetros da experiência anterior nas metrópoles europeias.

Dessa maneira, a metodologia empregada foi a utilização dos relatos de viajantes estrangeiros como portadores de leituras ideológicas sobre os locais descritos, relacionando percepção do meio e comportamento geográfico (CAPEL, 1973).

Para a análise do livro de Bates, foram inicialmente destacadas do corpo da obra as citações referentes à cidade e a seus diferentes aspectos, tais como arquitetura, urbanismo, vida social, política e econômica, composição étnica, etc. De posse desses dados, o passo seguinte foi agrupar as citações que tratavam de temas comuns ou afins, formando um painel da cidade, reunindo suas menções aos vários aspectos da cidade e da vida de seus habitantes.

Formado este painel, procuramos examinar suas citações com o intuito de destacar e dar coerência à visão do autor sobre a cidade. Também procuramos destacar as afirmações que de alguma maneira pudessem ser polêmicas, tanto naquela época como no momento atual.

Os tópicos utilizados para a formação do painel sobre a cidade de Belém constante no livro de H. W. Bates foram os seguintes: primeiras impressões da cidade; características geográficas da cidade; descrições de casas e do povoado de Nazareth; caminhos, avenidas e estradas; vegetação na cidade; animais na cidade; condições de vida; atividades econômicas; os poços públicos; vida política e administrativa; população e tipos humanos; relações sociais; religiosidade e festas religiosas.

\section{VIAGENS, VIAJANTES E SEUS RELATOS}

$\mathrm{O}$ ato de viajar sempre foi uma constante através da história humana, assim como o hábito de levar diários de viagem. No século XVIII, pode-se dizer que se alcançou o auge das viagens, pelo papel decisivo que estas representaram no debate cultural e científico europeu. O viajante dessa época tinha como características essenciais a preocupação pela fidelidade e a curiosidade universal, ou seja, o olhar em direção a horizontes distantes, cujas paisagens e organização social os incentivavam a refletir sobre os grandes problemas intelectuais do 
século: a origem e evolução das sociedades, o problema da unidade do gênero humano (questionado pela variedade de povos), o "funcionamento da Terra" e da natureza e as razões da diversidade de crenças religiosas (CAPEL, 1985).

A falta de dados concretos e de observações reais para resolver os enigmas geográficos que ainda restavam no século XVIII, aliado à cobiça por riquezas de terras desconhecidas, foram os motivos propulsores para a organização de expedições científicas com patrocínio governamental e poderosa infraestrutura. Por isto, as expedições reuniam dois planos diferentes: o técnico-científico e o político-militar (ATENEO DE MADRID, 1991).

$\mathrm{O}$ interesse pelas viagens gerou uma demanda por literatura de viagens:

Una vez en su casa, rodeado de libros, diarios y memorandums, el viajero se enfrenta a la ardua tarea de redactar un libro de viajes. Para ello deberá intentar dar forma coherente, y agradable, a la inmensa masa de información escrita que posee, además de tratar de ordenar sus impresiones, sus vivencias, sus reflexiones y sus simpatías (FREIXA, 1993).

\section{HUMBOLDT - PROTÓTIPO DO VIAJANTE NATURALISTA DO SÉCULO XIX}

Diferentemente do viajante ilustrado que se atinha à fidelidade, à informação detalhada, em suma, a uma atitude descritiva, aplicando as luzes da razão, o viajante do início do século XIX é considerado romântico, pois procurava a sensação e recriação de um mundo ideal, afastado da realidade, ou seja, via a paisagem de maneira idealizada. O espírito da ilustração que gerou a preocupação enciclopédica, de verdadeiro colecionador, dá lugar ao cientista altamente especializado, cuja expressão máxima encontramos na figura de Alexander von Humboldt (1769-1859), considerado um dos pais da moderna ciência geográfica (CAPEL, 1981). A ideia-chave de sua obra foi a busca da "harmonia" que existia na natureza, a qual via como a reunião em um todo de partes intimamente relacionadas. Procurava comparar as paisagens que estudava com as de outras partes do mundo. À concepção imóvel da natureza que imperava no sistema científico do século XVIII, com seus sistemas de classificação fixos e rígidos, contrapunha uma visão histórica e dinâmica dos acontecimentos, com o evolucionismo da ciência do século XIX (CAPEL, 1981).

Além das influências científicas, Humboldt foi fortemente influenciado pelo movimento romântico alemão, que encontrava máxima expressão na filosofia e na literatura, a ponto de Capel perceber em Humboldt um autêntico precedente da moderna geografia da percepção, pois ele “...había escrito magníficas páginas 
sobre estas geografías personales y sobre esas imágenes mentales que a veces hunden sus raíces en el mito y la leyenda" (1981). Humboldt, citando Hegel, aceita que o mundo exterior não existe para nós senão através da intuição, o refletimos dentro de nós mesmos (CAPEL, 1981).

\section{VISÕES URBANAS NOS LIVROS DE VIAGEM}

O que denominamos "visões", ou "paradigmas", que se impõem como maneiras de abordagem da realidade, suscitaram as diversas crises epistemológicas por que tem passado a Geografia. Isto parece haver sido superado com o surgimento da Geografia da Percepção. Se o objeto da ciência geográfica é a análise das relações entre o homem e seu meio natural, dentro de uma visão mais tradicional se considerava que o homem adaptava sua ação segundo as características do meio. Esquecia-se assim o que foi precisamente um dos grandes descobrimentos da Geografia atual: o papel decisivo da percepção humana na formação de uma imagem do meio real: é esta imagem que influi diretamente sobre o comportamento humano e não o meio "real" (CAPEL, 1973). Portanto quando falamos de ideia ou imagem de uma cidade, o mais correto seria falar de imagens no plural. Não falar de uma ideia de cidade, mas de ideias (GANAU CASAS, 1992).

Essa multiplicidade de abordagens aparece aliada às intensas transformações sofridas pela cultura urbana, que, aliada ao intenso desenvolvimento dos meios de comunicação de massa desemboca em uma utilização crescente de temáticas urbanas. A literatura, desde o século XIX, “....se hizo eco de estas transformaciones que estaban afectando a sus ciudades, incorporando entre sus temas todo aquello relacionado con lo urbano, en su sentido lato, ya como escenario en donde se mueven los personajes, ya la propia vida cotidiana de sus habitantes, o los conflictos sociales que en ella aparecían” (SUNYER MARTÍN, 1991).

As alterações da paisagem urbana, rural ou natural, ou seja, a permanente transformação do espaço geográfico também aparece descrita nos guias ou relatos de viagem. Esta descrição traz implícita uma valoração do descrito. O mundo real é apreendido através de filtros como são os sistemas de valores. Isto tanto no século XIX como no mundo atual.

Todas os juízos de valor emitidos pelos autores quando expressavam sua opinião sobre diversos assuntos que afetavam a sociedade no momento da publicação destes levam implícita uma posição ideológica. Por isso a Geografia da Percepção pode contribuir positivamente para o possível uso dos relatos de viagem na análise e difusão de ideias e estereótipos, pois os viajantes, como homens 
de seu tempo, carregavam ou eram influenciados pelo ambiente intelectual da época (ideias filosóficas ou estéticas, crenças religiosas ou preconceitos políticos) e providos de ideias científicas sobre população, recursos, clima, relevo, etc. (CAPEL, 1989).

\section{A EXPEDIÇÃO DE HENRY WALTER BATES}

Henry Walter Bates nasceu em Leicester em 18 de fevereiro de 1825 e faleceu em Londres em 16 de fevereiro de 1892. Sua grande viagem à Amazônia foi organizada juntamente com A. R. Wallace e com os auspícios do Museu Britânico. O livro que abordamos em tradução espanhola foi El naturalista por el Amazonas ${ }^{1}$, publicado originalmente em inglês com o título de The Naturalist on the River Amazons. Esta obra foi publicada em espanhol em três tomos; utilizamos o tomo I, denominado Pará (127 p.), que trata do período de sua saída de Liverpool em 26 de maio de 1848 até o início de sua grande viagem aos rios Tapajós e Amazonas em 6 de novembro de 1851. Seu tempo de permanência em Belém foi de um ano e meio, intercalado com diversas incursões ao interior da floresta amazônica.

Wallace regressou à Inglaterra em 1852 e Bates seguiu na Amazônia. Percorreu o leito do rio Amazonas estudando a fauna da região, regressando à Inglaterra apenas em 1859, portanto onze anos depois da partida. Foi um estudioso dedicado que introduziu o conceito de mimetismo, sendo que tanto Darwin como Wallace lhe devem dados de grande importância que serviram de apoio à teoria da seleção natural.

No prólogo de seu livro, Bates informa alguns dados de interesse sobre a sua viagem. Informa que, no outono de 1847 , Wallace lhe propôs uma expedição conjunta ao rio Amazonas, com o propósito de estudar a história natural de suas margens, e que tinham como objetivo realizar, por conta própria, uma coleção de objetos, vendendo em Londres os espécimes duplicados para fazer frente aos gastos da viagem. Procuravam reunir fatos que pudessem resolver o problema da origem das espécies (BATES, 1984; BATES, 1984, p. 8).

Quanto à publicação de seu relato de viagem, realizada apenas onze anos após o seu retorno, informa que o realizou por insistência de Charles Darwin, pois ao retornar à Inglaterra se encontrava “...muito deprimido, tanto de saúde como de ânimo, depois de residir por onze anos a quatro graus do equador, três dos quais, os últimos, os passei em zona selvagem, a 1.400 milhas das costa..." (BATES, 1984, p. 8).

\footnotetext{
A edição utilizada foi Barcelona: Laertes S. A., 1984, tradução de Marta Perez.
} 


\section{VISÕES URBANAS NO LIVRO DE H. W. BATES}

Partindo dos tópicos analisados do livro de Henry Walter Bates, destacados na introdução, faremos agora a análise de tais tópicos, ressaltando que a tradução, livre, foi realizada diretamente da versão em espanhol.

\subsection{VISÕES URBANAS SOBRE BELÉM DO PARÁ}

Bates descreve o aspecto da cidade no momento de sua chegada:

Está construída sobre uma franja baixa de terra, que tem uma única elevação rochosa no extremo sul; portanto não proporciona ao curioso uma visão de anfiteatro do rio; porém os edifícios brancos coroados por duas vertentes de telhas vermelhas, as numerosas torres e cúpulas de igrejas e conventos, as copas das palmeiras, que, após retroceder, se destacam por detrás das edificações com contornos bem definidos contra o azul claro do céu (...). A selva perpétua amuralha a cidade por todas as partes em direção a terra adentro (...). O porto estava (...) cheio de embarcações de nativos e outras embarcações grandes e pequenas e o barulho dos sinos e o lançamento de fogos de artifício anunciando o nascer de um dia de festa católica e romana, comprovavam que a população já estava desperta tão cedo (BATES, 1984, p. 16).

Descreve então os edifícios da cidade e sua modificação ao percorrer a cidade do porto em direção aos arrabaldes.

O autor também comenta sobre as características físicas de Belém do Pará, tais como a descrição do sítio urbano e a morfologia do terreno:

A cidade se ergue sobre uma porção de terra formada pela confluência dos rios Guamá e Pará. Como já havia dito antes, a selva que cobre toda a região se estende quase até as ruas do povoado (...). A superfície, ainda que baixa em seu conjunto, apresenta ligeiras ondulações, de modo que as zonas de terra seca aparecem alternadas com zonas de terrenos pantanosos (...).

A cidade está construída no lugar edificável mais adequado para um porto de entrada à região do Amazonas e com o tempo há de converter-se em um vasto empório... (BATES, 1984, p. 23; 46-47).

Nas descrições do clima da cidade, deixa transparecer sua preocupação científica. Informa as temperaturas máximas e mínimas, épocas de chuva, etc. Mas ultrapassa a mera enumeração de dados, incluindo descrições romanceadas da dinâmica do clima. Também procura enriquecer sua exposição introduzindo opiniões de residentes estrangeiros, estabelecendo comparações com o clima de seus países de origem, como quando cita que “...os residentes norte-americanos 
dizem que o calor não é tão opressivo aqui como o é no verão em Nova Iorque e Filadélfia. A umidade é, evidentemente, excessiva, porém as chuvas não são tão torrenciais e contínuas na estação úmida como em muitos outros lugares tropicais" (BATES, 1984, p. 19).

Bates descreve com maior detalhe o povoado de Nazareth, onde ele e Wallace alugam uma casa após curto período em outra habitação. Este povoado situava-se a uma milha e meia da cidade e muito próximo da selva. Possuía, portanto, as condições ideais para as pesquisas que pretendiam realizar. A estada neste local serve também para descrição da residência que passam a ocupar. "A casa era um edifício quadrado e tinha quatro cômodos de igual tamanho. $\mathrm{O}$ telhado se projetava em todo o seu perímetro, formando uma larga galeria fresca e agradável, em que dava gosto sentar-se a trabalhar" (BATES, 1984, p. 71).

A descrição das vias de comunicação são importantes pois acrescentam informação sobre a organização urbanística da cidade no período. Além da estrada que ligava o centro urbano às cercanias da cidade, Bates descreve a "Estrada das Mangubeiras", ou "estrada de mongubas". Também menciona a "estrada principal da selva", que se estendia até o Maranhão, assim descrita por Bates:

Muito próximo de nossa porta se iniciava a estrada principal da selva. Tinha tamanho suficiente para dois homens a cavalo de frente e se ramificava em três direções, sendo a linha mais importante a que conduzia ao povoado de Ourem, a uma distância de 50 milhas. Antes esta estrada se estendia até Maranham, mas fazia tempo que não era usada e o descuido havia feito das suas, deixando-a quase impraticável entre Pará2 e Ourem (BATES, 1984, p. 72).

Em um meio natural formado pela selva amazônica e cortado por numerosos canais fluviais, o transporte fluvial se destaca sobre os demais. Esta realidade foi observada por Bates da seguinte forma:

Os igarapés e furos ou canais, que são infinitos em número neste grande delta fluvial, são característicos do país. A terra está coberta, por todas as partes, de selvas impenetráveis, de tal modo que as casas e povoados estão todos situados às margens dos rios, realizando-se pela água a maioria das comunicações. Esta vida semi-aquática das pessoas constitui um dos traços mais característicos do país (BATES, 1984, p. 88).

Tratando-se de um naturalista, é normal a menção à existência de animais e plantas na cidade, ainda mais que Belém do Pará encontrava-se envolvida pela floresta: "As copas, escuras e maciças das sombrias mangueiras se viam por todas as partes entre as casas, junto a laranjeiras e limoeiros perfumados e verdes

2 Era essa a denominação com que o autor se referia à cidade de Belém. 
rodeados por sua vez por toda a sorte de árvores tropicais, algumas em flor, outras carregadas de frutos em diferentes etapas de maturação" (BATES, 1984, p. 18).

Quanto aos animais, as referências são muitas. Algumas tratam da diferença entre os animais que habitavam a cidade e aqueles que viviam na floresta. Realiza também a descrição dos pássaros da região. Porém sua atenção principal se voltava para os insetos, que eram sua especialidade, detendo-se nas saúvas e nos prejuízos que causavam para a agricultura e para os estoques de alimentos das residências. Observou também o hábito dos moradores em transformar animais silvestres em animais domésticos, como no caso dos macacos. Por fim, fala sobre a constante presença de serpentes na cidade, tendo em vista a proximidade da selva.

Bates também realiza explanação sobre as condições de vida da cidade. $\mathrm{Na}$ página 45 de seu livro, comenta sobre os resultados para a vida urbana dos enfrentamentos entre brasileiros e portugueses no início do século XIX, que causaram um grande decréscimo populacional: a cidade passa de 24.500 habitantes em 1819 para 15.000 em 1848, segundo seu relato.

Comenta também sobre o grau de salubridade, medido pela existência ou não de epidemias. Após a epidemia de 1819, que atacou sobretudo os índios, a cidade apresentou salubridade invejável até a epidemia de febre amarela de 1850, sucedida em 1855 por uma epidemia de cólera. Desde então, o quadro foi melhorando, com Bates realizando elogios rasgados às condições do clima da cidade: "A temperatura uniforme, o verdor perpétuo, o ar fresco da estação seca, quando o calor se encontra contrabalançado pelas fortes brisas marítimas e a moderação das chuvas periódicas, todo isto faz do clima um dos mais deliciosos sobre a face da terra (BATES, 1984, p. 48)".

Bates descreve as diversas atividades econômicas existentes na cidade. É interessante a correlação que realiza entre as diversas raças e classes sociais e as atividades econômicas a que normalmente se dedicam, as quais destacamos aqui:

O comércio, tanto o atacadista, quanto o varejista, estava em mãos dos 2.500 portugueses que havia no lugar. $\mathrm{O}$ artesanato era praticado sobretudo pelas gentes de cor: mulatos, mamelucos, negros livres e índios. Os brasileiros de cunha mais elevada são pouco aficionados aos detalhes triviais do comércio urbano, e se não podem ser mercadores atacadistas preferem viver como plantadores no campo, por pequenas que sejam suas fazendas e ganhos. Os negros configuravam a classe dos lavradores e moços de corda, os índios eram em todas as partes os barqueiros e constituíam a tripulação exclusiva de inumeráveis embarcações de todos os tamanhos e formas que comerciavam entre Pará e o interior (BATES, 1984, p. 53). 
Suas referências à administração do país sempre são, digamos, favoráveis. Cita a boa conservação de Belém graças aos cuidados do governo para evitar o avanço da selva. Também cita os "presidentes empreendedores" que construíram grandes e belas avenidas.

Bates reserva grande parte do seu livro à descrição das festas religiosas, em que percebe o auge da vida citadina, em que se pode observar os costumes e a idiossincrasia do povo da cidade. Comenta a grande quantidade de festas, que o governo procurou reduzir a fim de beneficiar as atividades produtivas, pois as percebia como um pretexto para as pessoas não trabalharem: “...pouco ou nada se trabalhava em nenhuma parte enquanto duravam as celebrações, de modo que sua tendência corruptora se fazia patente. Não se tarda em compreender que a religião é, para os paraenses, mais um entretenimento lúdico que algo importante que há que praticar com seriedade” (BATES, 1984, p. 103).

Descreve também a forma de organização das festas, seus meios de financiamento e custo aproximado e seu uso para ostentação das classes mais abastadas. Impressiona a Bates sobretudo a diversidade racial da população e a beleza das mulheres. A esse respeito realiza uma associação entre a população, suas condições sociais e o cenário natural: "Foi uma pura fantasia, mas me ocorreu pensar que, a mescla de miséria, luxo e beleza naquelas mulheres harmonizavam extraordinariamente com o resto da cena; assim resultava assombroso à vista a combinação do caudal da natureza com a pobreza humana" (BATES, 1984, p. 18).

Quanto à diversidade racial, Bates descreve sobretudo as raças negra e indígena, bem como suas mesclas entre si e com a raça branca, bem como a proporção de cada raça na composição da sociedade.

Em suas descrições das diversas mestiçagens possíveis, Bates tem a preocupação de não parecer discriminatório, pois diz, por exemplo, mestiçagem de branco e índia e vice e versa. Seu esforço é louvável, mas como ele mesmo relata na pág. 53, a emigração europeia foi quase exclusivamente de varões, o que denota que as relações sexuais levavam a marca do colonialismo e da opressão social, sendo que a miscigenação era preponderantemente de brancos homens com índias ou negras.

Apesar de suas opiniões condescendentes em relação aos negros, não há nenhuma menção contrária à escravidão vigente no país. Unicamente fala do trato benevolente que recebem os escravos de parte de seus amos. Nenhum comentário sobre o absurdo da situação de um ser humano sujeito à escravidão por outro. Em assuntos políticos e, portanto polêmicos, Bates parece refugiar-se em sua condição de cientista. Deste modo, o autor reproduzia uma atitude ainda vigente em certos meios científicos, que, ao abster-se de opinar, pensam não estar assumindo uma opção política. 
No que diz respeito aos índios, Bates faz comentários bastante completos, incluindo inclusive descrições antropométricas. Apesar de geralmente colocar-se em defesa destes, cai presa de raciocínios dicotômicos. Descreve, por exemplo, as diferenças que segundo ele existem entre as tribos costeiras e as do interior. Para ele, as tribos do litoral estavam muito mais avançadas em grau de civilização e os "selvagens de terra adentro, (...) levavam uma vida errante, (...) aproximando-se à civilização muito raramente para roubar as plantações das tribos costeiras..." (BATES, 1984, p. 90). Em comparação às tribos costeiras, “....eram de disposição amável e receberam os primeiros colonos portugueses com grande cordialidade". Neste ponto, a tradutora do livro se vê obrigada a inserir uma nota: "Aqui Bates se deixa influenciar pelo ‘bom selvagem’ de Rousseau, pois não devemos esquecer que os tupinambás eram antropófagos e o foram até muito tempo depois de iniciada sua relação com os portugueses" (BATES, 1984, p. 90). Mas sua declaração mais preconceituosa é aquela em que declara que os filhos de brancos e índios em geral se transformavam em "cidadãos brasileiros honrados" e que, por isto, "encontraremos poucos motivos para lamentar o destino da raça [indígena]" (BATES, 1984, p. 93). Nesta declaração, encontramos eco das teorias da supremacia racial dos brancos europeus frente aos "atrasados" indígenas.

Em relação aos enfrentamentos da Cabanagem, conflito político ocorrido na província, sua análise cai em uma abordagem maniqueísta. Embora reconhecendo que os "errôneos cidadãos principais" foram os que causaram os ódios raciais, sempre os identifica como "amigos da paz e da ordem". Por outro lado, referese ao povo sublevado com adjetivos como "vasto exército de gentes de cor meio selvagens", "híbridos", "seções mais ignorantes e fanáticas dos híbridos e a população indígena", "revolucionários de tez escura"; todos com uma clara conotação depreciativa. Já os nativos que colaboraram com as forças legais são chamados de "tribos inteiras de índios amigos e certos grupos de negros e mulatos de melhor disposição”. Parece claro para que lado se inclina Bates.

Mas os comentários também adquirem uma conotação racista, o que nos permite abordar outro tema especialmente polêmico: o das relações raciais e da existência do racismo. Antes de empreender sua viagem, Bates preparou-se através da leitura de obras sobre a nação e a região que ia visitar. Isto se deduz de comentários que faz no transcurso do livro. Recordemos aqui o mecanismo da discriminação. Um preconceito pode surgir da ignorância, do não conhecimento. Este pode levar a mais preconceito, indefinidamente em um processo que se autoalimenta. Só o conhecimento pode levar à desmistificação, contribuindo para a superação da discriminação racial. Tal processo parece haver ocorrido com Bates, que se admirava de refutar pela observação direta preconceitos difundidos 
por outros autores. Mas quando declara que os negros são tão confiáveis como os brancos e mestiços transparecem velhos estereótipos preconceituosos.

Bates relata os frequentes conflitos entre nativos e portugueses, ressaltando que a ira dos nativos era dirigida unicamente aos portugueses e não aos demais estrangeiros residentes na cidade. Entendemos que, ao fazer esta colocação, Bates procurava demonstrar que o Brasil era um país seguro, o mesmo acontecendo com seus comentários sobre a salubridade do clima, pois parece ter a intenção de desmistificar preconceitos sobre o tema.

\section{A MORALIDADE EM UMA CIDADE DOS TRÓPICOS}

Reunimos neste tópico as observações do autor que reputamos de maior conteúdo ideológico. Em certo ponto, Bates compara Belém com outras cidades portuárias brasileiras, servindo-se de informações de terceiros. Considera-a mais simples, pacífica e cordial que as outras cidades “...de modo que os assassinatos que tão má reputação levam às províncias sulistas, eram aqui quase desconhecidos" (BATES, 1984, p. 52-53), mas que “...por outra parte os nativos do Pará eram muito inferiores aos brasileiros do Sul no que concerne à energia e capacidade de trabalho" (BATES, 1984, p. 53). Encontramo-nos com uma afirmação polêmica, mais, no momento, podemos contentar-nos com sua enumeração dos motivos responsáveis por este estado de coisas:

Como as provisões e os aluguéis das casas eram baratos e as necessidades das pessoas escassas - se conformavam [os habitantes do Pará] com comida e moradia de uma qualidade que seria rechaçada de imediato pelos mendigos ingleses-, os paraenses passavam a maior parte do tempo cedendo a indulgências sensuais e entretendo-se com diversões que o governo e os cidadãos de posses lhes proporcionavam gratuitamente (BATES, 1984, p. 53, grifo nosso) ${ }^{3}$.

Não podemos precisar aqui o que Bates quer dizer exatamente com "indulgências sensuais", tampouco que diversões eram estas proporcionadas pelo governo e pelos cidadãos ricos. O mais próximo a isto que ele descreve, são as festividades religiosas, das quais ressalta seu caráter corruptor, pois nos vários dias de festa praticamente não se trabalhava e o povo as encarava muito mais como entretenimento lúdico do que com a seriedade de uma cerimônia religiosa. O mesmo assunto é abordado em conversação que manteve com certo senhor Zanin, sobre os motivos que levam os trabalhadores contratados a abandonarem

Afirmações quase idênticas a esta encontramos em nosso outro trabalho sobre viajantes (ver SILVA, 2002). 
seus postos: a abundância de terra desocupada, a liberdade existente, o estado de coisas produzido pela vida fluvial e meio selvagem das pessoas e a facilidade de subsistir trabalhando com moderação. $O$ autor cita um viajante alemão, Burmeister ${ }^{4}$, que

...disse uma vez que a contemplação da selva brasileira provocava nele uma sensação de dor, devido a que a natureza exibia um espírito de egoísmo inesgotável, de entusiasta emulação e de artifício. Opinava que a suavidade, a sobriedade e o repouso que se desprendiam das cenas de bosque européias eram muito agradáveis, e que sem dúvida constituíam uma das causas da moralidade superior das nações de nosso mundo (BATES, 1984, p. 64-65, grifo nosso).

Bonitas imagens mentais, mas carregadas de juízo ideológico. Constatamos como importantes homens da ciência da época opinavam que a selva era responsável pela suposta imoralidade do povo brasileiro. Bates não chega a pôr em dúvida esta questão. Para ele, o importante era descobrir as causas deste estado de coisas:

Talvez seja em parte a posição degradada que tem ocupado as mulheres desde tempos ancestrais o que faz que as relações entre ambos os sexos hajam estado e sigam estando a um nível tão insatisfatório e que a moralidade privada se encontre no Brasil em uma decadência tão penosa. No Pará creio que agora se tem produzido um certo desenvolvimento, mas em tempos passado as uniões promíscuas pareciam ser a regra geral entre os membros de todas as classes, sendo as intrigas e os devaneios amorosos as preocupações mais importantes da maior parte da população (BATES, 1984, p. 54, grifo nosso).

Para o autor, uma possível causa seria então a posição subalterna da mulher, condição esta que em última instância atribuía aos antepassados portugueses. A seguir rechaça a teoria determinista da influência do clima e afirma que não seja responsabilidade das instituições.

Não me convence a teoria segundo a qual tal estado de coisas é uma necessidade que depende do clima e das instituições, já que residi em pequenos povoados do interior, onde os costumes e a moralidade dos habitantes eram tão puros como em lugares similares da Inglaterra (BATES, 1984, p. 54).

\footnotetext{
4 Hermann Burmeister (1807-1892), naturalista. Percorreu em 1850 as províncias brasileiras do Rio de Janeiro e de Minas Gerais, de onde regressou em 1852. Posteriormente percorreu o Uruguai e a Argentina, radicando-se em Buenos Aires em 1861, onde exerceu funções científicas e acadêmicas (Dados da Enciclopédia Universal Ilustrada, Barcelona, Espanha: Espasa-Calpe, 1958).
} 
Como podemos perceber, o autor incorre em contradição, pois Burmeister, citado por ele, considera o estado mental provocado pela selva como causador de tais impulsos sensuais, o que configuraria uma postura determinista.

\section{CONSIDERAÇÕES FINAIS}

De maneira geral, podemos dizer que a visão que Bates tem de Belém era de uma cidade organizada, dinâmica, saudável, mas que enfrentava o sério desafio da falta de apego da população às atividades laborais.

Destacamos sobretudo suas excelentes qualidades de observador perspicaz e de narrador agradável e capaz de criar belas imagens mentais, como quando compara a árvore de maçaranduba com elementos urbanos: "se eleva por cima das demais árvores da selva, destacando-se como o faz uma catedral sobre os telhados dos edifícios de uma cidade" (BATES, 1984, p. 80).

Cabe destacar também um componente essencial de seu livro: a defesa sem quartel que faz do Brasil. Tal ocorre na questão das epidemias, defendendo a salubridade do clima da cidade. Também quando ressalta ser a cidade segura para estrangeiros residentes ou visitantes. Não pudemos averiguar se sua postura se deve a favores recebidos do governo brasileiro ou uma maneira de evitar problemas diplomáticos a futuras expedições e mesmo incentivar novas explorações.

Outra questão a destacar seriam suas constantes críticas aos portugueses, considerando-os geralmente como retrógrados e supersticiosos. Parece-nos que, novamente, Bates assume a defesa do Brasil, que se tornara independente há pouco, atribuindo a culpa dos problemas da época à herança portuguesa.

As críticas a determinadas posturas ideológicas do livro não o desmerecem em absoluto. Trata-se de excelente narrativa de um pesquisador sério que procura descrever com riqueza de detalhes não só a fauna e a flora da região amazônica, como também sobre a vida cotidiana de uma cidade inserida na grande floresta, proporcionando conhecimento sobre aquele período histórico.

Percebe-se claramente pela análise do texto relativo à cidade de Belém do Pará como a descrição é atravessada, e não consegue fugir, da figura do "préconceito', formado pelas ideias que o autor traz de sua bagagem cultural, de seu meio e de sua época. Tal aspecto, presente em vários dos tópicos abordados pelo autor, fica muito claro quando analisa as questões relativas à moralidade da vida em uma região tropical. 


\section{REFERÊNCIAS}

ATENEU DE MADRID. La ciencia española en Ultramar (Actas de las $1^{\mathrm{a}}$ s jornadas sobre España y las expediciones científicas en América y Filipinas). Madrid, Espanha: Doce Calles, 1991.

BATES, H. W. El Naturalista por el Amazonas. Vol. I - Para. Barcelona: Laertes S. A., 1984.

CAPEL, H. Percepción del medio y comportamiento geográfico. Revista de Geografía, Barcelona, Espanha, vol. VII, n. ${ }^{\circ} 1$ y 2, 1973.

Filosofía y ciencia en la geografía contemporánea: una introducción a la geografía. Barcelona, Espanha: Barcanova, 1981.

- Geografía y arte apodêmica en el siglo de los viajes. Geo Crítica, Barcelona, Espanha, n. 56, 1985.

- Historia de la ciencia e historia de las disciplinas científicas. Geo Crítica, Barcelona, Espanha, n. 84, 1989.

FREIXA, C. Os ingleses y el arte de viajar: una visión de las ciudades españolas en el Siglo XVIII. Barcelona, Espanha: Ediciones del Serbal, 1993.

GANAU CASAS, J. La Idea de ciutat a Lleida. Lleida, Espanha: Pagès Ed., 1992.

SILVA, M. W. Visiones urbanas en los relatos de viaje: el viaje del naturalista Henry Walter Bates a la Amazonia en el siglo XIX. Barcelona, Espanha: Escuela Técnica Superior de Arquitectura del Vallès, Universidad Politécnica de Cataluña, 1995. 44 f. [Monografia de Especialização em "Urbanismo, Ciudad, Historia"].

A paisagem urbana da cidade de São Paulo na visão de viajantes estrangeiros, 1808-1858. Rio Claro: Instituto de Geociências e Ciências Exatas da Universidade Estadual Paulista, 2002. 234 p. [Dissertação de Mestrado em Geografia - Área de Concentração em Organização do Espaço].

SUNYER MARTÍN, P. La idea de ciudad en la literatura española del siglo XIX: la ciudad española en la obra de Pedro A. De Alarcón (1833-91). In: CAPEL, Horacio et. al. (orgs.). Ciencia e ideología en la ciudad: I Coloquio Interdepartamental. Valencia, Espanha: Generalitat Valenciana, 1991. vol. 1. 